\title{
VISÕES DE CIÊNCIAS DE PROFESSORES DE QUÍMICA: A MÍDIA E AS REFLEXÕES NO AMBIENTE ESCOLAR NO NÍVEL MÉDIO DE ENSINO
}

\author{
Nyuara Araújo da Silva Mesquita e Márlon Herbert Flora Barbosa Soares* \\ Instituto de Química, Universidade Federal de Goiás, Campus II, CP 131, 74001-970 Goiânia - GO, Brasil
}

Recebido em 3/4/07; aceito em 27/3/08; publicado na web em 26/9/08

\begin{abstract}
SCIENCE INSIGHT'S OF CHEMISTRY TEACHERS: MEDIA AND REFLECTION ON HIGH SCHOOL ENVIRONMENT. The present paper discusses the influence of TV and general media on students scientific ideas and the teacher's perception of this influence on students during class time. 17 high-school chemistry teachers with teaching degree, working in state schools, were interviewed. The interviews showed that both, teachers and students, have a positive opinion of science and the scientist. According to their teachers, students' positive view of science is greatly influenced by TV. The developed study shows how important epistemology is in teachers' college formation to offer them a critical perception of science treated in general media.
\end{abstract}

Keywords: science insights; media and television; epistemology.

\section{INTRODUÇÃo}

O uso da imagem tem papel de fundamental importância na história da humanidade. Os primeiros registros de imagens encontradas em cavernas datam de cerca de 17 mil anos na gruta de Lascaux na França. ${ }^{1} \mathrm{O}$ desenvolvimento do homem, durante milênios, foi descrito por meio de pinturas rupestres.

De acordo com Carmo, ${ }^{2}$ a escrita originou-se do desenho:

No início, os símbolos gráficos eram abstrações de formas encontradas na natureza, tais como animais, homens, o sol, a lua, etc. Na medida em que o volume de informações crescia, estes símbolos foram sendo simplificados para facilitar o registro e economizar espaço. Assim, o desenho de um pássaro foi se transformando até restarem traços simples que, para os que estavam familiarizados com a simplificação feita, resumiam o desenho original de um pássaro (p. 5).

Com o surgimento da escrita, a comunicação não necessita mais da presença física das pessoas, mas pode ocorrer, também, entre aqueles distantes uns dos outros no tempo ou no espaço. ${ }^{1}$

Desde os copistas, que produziam manuscritos em papiro e pergaminho, passando pela invenção da imprensa por Gutemberg no século $\mathrm{XV}$, pelo desenvolvimento da fotografia e do cinema até chegar à internet e à TV digital, escrita e imagem associaram-se no desenvolvimento de processos e técnicas de comunicação que culminaram na construção de um mundo globalizado em que informações audiovisuais levam poucos segundos para chegar a diversos pontos do planeta.

Neste cenário, a televisão configura-se como veículo de transmissão de informações de maior penetração e, devido ao seu largo alcance, tornou-se o principal instrumento de homogenização de hábitos, difusão de comportamentos e valores da sociedade globalizada. Em decorrência disto, a televisão e os programas por ela veiculados constituem-se em motivo de debates e discussões a respeito do papel e influência deste meio de comunicação no contexto cultural da atualidade.

Pesquisas mostram que as crianças e adolescentes passam mais tempo diante da televisão do que na escola. ${ }^{3}$ Tais estatísticas tornamse preocupantes à medida que a TV e o conteúdo por ela veiculado infiltram-se nos lares e nas mentes de crianças e jovens seduzindo-os através de imagens e sons e tomando para si funções que, até então, pertenciam à família e à escola. Nas palavras de Fusari: ${ }^{4}$

\section{A leitura e interpretação do mundo, realizada pela infância contemporânea, mostra-se como sendo feita, então, não mais através da família e da escola, mas, também, através do ambiente urbanizado de habitação e vida, dos grupos de mesma idade e dos "media" que estão presentes em suas horas livres, em suas ações e representações infantis cotidianas (p. 51).}

Escola e família encontram-se desafiadas na era da informação frente à imagem que se constitui em veículo de transmissão cultural que eclipsou o papel destes dois tradicionais fatores de socialização. ${ }^{5}$ A escola atual encontra ainda dificuldades para se articular em sua proposta pedagógica frente às possibilidades de acesso que seus estudantes têm em relação à "mídia imagético-eletrônica", ou seja, meios de comunicação que associam imagens e tecnologias para transmissão de informações. ${ }^{6}$

Os Parâmetros Curriculares Nacionais, ${ }^{7}$ documentos que sinalizam a educação no Brasil, orientam para o desenvolvimento de propostas educacionais que trabalhem reflexivamente sobre as programações midiáticas, incentivando a formação de uma postura crítica dos telespectadores-alunos, contrapondo-se assim, à passividade consumista tão presente nos jovens.

...é comum que crianças e jovens tenham acesso, pela televisão, a informações diversas que muitas vezes são fragmentadas, descontextualizadas, imprecisas, tendenciosas e até discriminatórias. Os alunos, embora ainda não tenham condições de compreendê-las plenamente, atribuem significado ao que vêem. Na escola, é possível provocar situações que permitam atribuir outros significados a esses conhecimentos e à construção de outros saberes a partir deles, assim como desenvolver atitude crítica frente aos conteúdos veiculados. ${ }^{7}$ 
Ressalta-se que ao se falar sobre a relação existente entre educação e televisão, deve-se deixar claro que o processo deve ir além do discurso da "análise crítica" proposta pelo sistema. Deve-se tratar a televisão e o conteúdo por ela veiculado como parte integrante da vida do aluno, como formadora de opinião, de juízos de valor. É preciso conhecê-la para estabelecer situações de comunicação que possam conduzir à construção de um conhecimento científico a partir de um universo familiar ao estudante, pois, segundo Arroio e Giordan: ${ }^{8}$

a informação e a forma de ver o mundo predominante nas sociedades atualmente provêm fundamentalmente da televisão, que atua de forma sedutora e aparentemente despretensiosa, alimentando e atualizando os universos sensoriais, afetivos e éticos que crianças, jovens e adultos levam para a sala de aula.

Desta forma, o ideário científico das pessoas, suas visões sobre ciências e sobre os fatos a ela relacionados podem também ser influenciados, em sua formação, pelas abordagens sobre o tema que são veiculadas na mídia televisiva, pois convivendo dia após dia com imagens e mensagens da televisão, crianças e adultos vão tecendo novas experiências, e novas formas de perceber o mundo e a si próprios. ${ }^{9}$

\section{MÉTODO}

A fim de obter informações a respeito de quais são as visões que o professor tem a respeito das concepções de ciência de seus alunos, além da forma com que estas concepções são influenciadas pela programação televisiva, foram entrevistados professores licenciados em química de escolas públicas e particulares de Goiânia.

Foram entrevistados 17 professores de unidades escolares localizadas em diferentes bairros da cidade de Goiânia - GO para que os resultados não levassem a um perfil único de professor e estudante. A escolha dos professores a serem entrevistados deu-se a partir de levantamento feito por $\mathrm{Cunha}^{10}$ sobre o quantitativo de professores licenciados em química e efetivos da rede estadual de ensino atuando no município de Goiânia no período de 2004/2005; outro fator considerado para a escolha foi a disponibilidade do professor em atender o pesquisador para a realização da entrevista.

Os 17 professores entrevistados têm como formação o curso de Licenciatura em Química, em universidades públicas, sendo que 16 deles foram formados na Universidade Federal de Goiás e 1 foi formado na Universidade Estadual de Goiás. Quando entrevistados, todos se encontravam em efetivo exercício da profissão, além disso, salienta-se que todos têm cargos efetivos na rede pública estadual de ensino do estado de Goiás, obtido por meio de concurso.

Foram organizadas entrevistas semi-estruturadas por considerarse que fornecem ao entrevistador liberdade para desenvolver cada situação em qualquer direção que considere adequada e que esta é uma forma de poder explorar mais amplamente uma questão. Tal escolha justifica-se ainda pelo fato de que, ao lidar com professores (educadores), tem-se um amplo leque de informações relacionadas ao cotidiano escolar que a entrevista estruturada poderia diminuir devido a sua característica de seguir um roteiro rígido de perguntas feitas a todos os entrevistados de maneira idêntica e na mesma ordem. ${ }^{11}$

O roteiro da entrevista passou por um pré-teste em que houve a realização de entrevista piloto com um professor efetivo da rede estadual de ensino. Após a análise deste piloto, foram realizadas algumas modificações que conduziram à entrevista definitiva (Quadro I). As entrevistas foram realizadas entre os dias 2/1/2006 e 12/5/2006.

$\mathrm{O}$ posicionamento dos professores foi analisado a partir das respostas dadas aos questionamentos feitos que objetivaram relacionar visões de ciência veiculadas na programação televisiva como um dos
Quadro I. Roteiro da entrevista semi-estruturada

1- Em sua opinião, qual a visão de ciência e de cientista que os alunos ingressantes no ensino médio têm?

2- Qual a provável origem dessa visão dos alunos?

3- Você discute, em sala de aula, com seus alunos, o papel e a importância da química como ciência no desenvolvimento humano? 4- Alguma vez você já levou algum programa de televisão para debater com seus alunos questões relacionadas à ciência, à química? Qual? Como aconteceu a aula?

fatores de influência na construção do ideário científico dos alunos. Esta investigação sobre ideário científico veiculado na mídia, construído pelos estudantes e trabalhado (ou não) pelos docentes, busca contribuir para a reflexão do professor sobre sua prática na educação científica, pois, segundo Cachapuz et al: $:^{12}$

Convém ponderar e discutir as deformações conjecturadas, que expressam, no seu conjunto, uma imagem ingênua profundamente afastada do que supõe a construção dos conhecimentos científicos, mas que se foi consolidando até se converter num estereótipo socialmente aceite que, insistimos, a própria educação científica reforça por acção ou omissão (p. 40).

Tendo em vista o largo alcance da televisão na vida dos jovens, optou-se pela realização de entrevistas com professores de química para que se pudesse delinear um quadro da relação mídia/ensino de ciências/química no ambiente escolar.

\section{RESULTADOS E DISCUSSÃO}

Embora seja de conhecimento geral e se encontrem na literatura referências às visões distorcidas que os alunos têm sobre ciência e sobre o cientista e que são parcialmente divulgadas na mídia, ${ }^{13} \mathrm{o}$ diferencial deste trabalho é que ele buscou realizar estas entrevistas investigando esta questão a partir da fala daquele que acompanha diariamente o aluno na construção e elaboração do seu conhecimento científico: o professor de química e, durante esta pesquisa, observar o modo como o próprio professor se posiciona em relação aos assuntos que dizem respeito à ciência ou à própria natureza do conhecimento que são embutidos na programação veiculada pela televisão.

Ao serem questionados sobre quais as visões de ciência e de cientista que eles percebem nos alunos que ingressam no ensino médio, $88 \%$ das respostas obtidas seguiram o mesmo padrão:

Pra eles a ciência e o cientista são coisas de outro mundo. Pra eles o cientista é uma pessoa louca e... parece que ele vive em outra realidade. (Professor 3 )

Bom, é... Os alunos que eu trabalho, a idéia que eles têm do cientista seria aquela que é passada pela mídia, né? Aquela pessoa reclusa, que se dedica ao máximo ao experimento dele, que não se importa com a aparência... Seria esse cara (Professor 12)

Acho que a visão de ciência e cientista é uma visão muito afastada deles. Eles vêem como algo inatingível, principalmente o cientista. Eles acham que é um outro ser, não é nem um humano. E a ciência "prá" eles não "tá" relacionada com o dia-a-dia, com a realidade, é sempre alguma coisa que vê na televisão, no jornal mas nunca algo acessível a eles. (Professor 13) 
$\mathrm{Na}$ visão de cientista que os professores relacionam aos alunos, o mesmo é caracterizado como uma pessoa dedicada ao seu experimento, reclusa, não muito sociável. É alguém que vive em outra realidade. Isso se deve, em parte, às idéias veiculadas, por exemplo, em desenhos animados, pelo cinema e pelos meios de comunicação em geral. ${ }^{12}$

Cabe aqui um parêntese sobre a universidade e seu papel na formação do licenciado em química. Ao responderem sobre as visões de ciência que eles (professores) detectavam nos alunos, deixaram transparecer, durante suas falas, um pouco de sua própria visão sobre o assunto. E nesse desvelar, pode-se observar que nenhum dos professores entrevistados mencionou alguma das visões de ciência que são discutidas na disciplina de epistemologia das ciências e que se mostram fundamentais para a compreensão da natureza do conhecimento científico.

Provavelmente, os professores não tiveram essa disciplina em seus cursos de graduação. Desta maneira, é importante que as universidades propiciem aos seus alunos, na formação docente, a oportunidade de conhecer como se compreende a ciência e o desenvolvimento científico ao longo dos tempos, pois só assim o professor formado terá condições de levar esse debate ao ensino básico, tendo condições de conduzir o jovem aluno a pensar e questionar sobre as posturas científicas assumidas e suas influências no mundo contemporâneo.

De acordo com os currículos e grades curriculares dos cursos de graduação do estado de Goiás, observa-se que epistemologia das ciências não constava nestas grades até 2004, sendo explorada apenas em nível de pós-graduação, no caso específico da Universidade Federal de Goiás. Ressalta-se que em um levantamento mais atual, a partir das matrizes curriculares das universidades e faculdades que oferecem o curso de licenciatura em química no estado de Goiás, a referida disciplina é oferecida e obrigatória na Universidade Federal de Goiás e na UniEvangélica. Na Universidade Estadual de Goiás, a disciplina é optativa, já na Universidade Católica e na UniAnhanguera, tal disciplina não consta na matriz curricular do curso em questão.

Quanto à provável origem das visões que os alunos têm sobre a ciência e sobre o cientista, $75 \%$ citaram a televisão, como pode ser observado nas falas a seguir:

É porque é uma visão passada através da própria mídia, dos filmes. Mostra o cientista lá dentro, aquela visão muito restrita. (Professor 6)

É uma visão que a mídia passa, bem longe... essas pessoas que ficam trancadas num laboratório. (Professor 9)

Eu acho que é bem mercadológica essa parte. Se a TV vende uma coisa, o público compra. (Professor 10)

Eu percebo assim que vem mais do que eles ouvem, vem através da televisão porque eles não têm o hábito da leitura. (Professor 16)

A televisão é vista como principal origem da visão distorcida que os professores detectam nos alunos sobre a ciência e o cientista. Essa visão é passada de maneira caricata por desenhos animados. Os programas televisivos voltados ao público infanto-juvenil, como desenhos animados, anúncios publicitários, entre outros, podem ser considerados discursos culturais sobre a vida social, que lhes sugerem um posicionamento sobre o mundo. ${ }^{9}$

A opinião dos professores vem corroborar uma das idéias discutidas no presente trabalho de que as visões de ciência veiculadas pela televisão tendem a influenciar os jovens nas suas concepções sobre a ciência e podem, desta forma, obstacularizar tanto a aprendizagem dos conceitos científicos quanto a compreensão sobre a estreita relação existente entre ciência, tecnologia e sociedade.

Detectou-se na fala de cerca de 53\% dos professores, ao comentarem as visões de ciência e cientista dos alunos e ao discorrerem sobre suas próprias práticas na explicação da ciência no desenvolvimento humano, uma concepção positivista sobre a atividade científica, como se pode observar nas falas:

No primeiro ano sempre a gente ensina o que é o método científico e eles gostam muito dessa parte porque eles vão entender realmente é... a parte interessante da ciência, o quê que é a ciência. E eles entendem o que é a hipótese, o que é o método científico a partir das experiências até chegar nas leis. (Professor 2, grifo nosso)

Eu acho que é isso...você vê, ciências, o que é bom? A gente ter um laboratório "pros" meninos fazerem experiências, tudo... a gente pode fazer em sala mas são poucas experiências que pode fazer em sala. E aí, porque eles gostam da parte prática, eles gostam quando você põe eles "prá" fazer mesmo, eles gostam. Mas a maioria das escolas não tem laboratório, né? Então tinha que incentivar. Então, acho que a questão mais é essa aí, essa falta de...de uma parte prática que vai ajudar eles na aprendizagem. (Professor 4, grifo nosso)

"Pra" eles verem o papel da ciência eu pego assim muito o cotidiano deles, aquela questão de...de remédio, de alimento, de vestuário, esses exemplos "prá" puxar a origem da coisa. Assim, o "cara" descobre um composto e aquilo vai servir "pra” fazer um pneu ou fazer uma roupa e que vai melhorar sua vida. (Professor 10, grifo nosso)

Então a gente sempre "tá" enfocando essa questão de buscar, de mostrar, tudo ele tem que observar e procurar respostas, né? Para aquelas perguntas que eles têm no cotidiano, né? Então é importante eles observarem as questões naturais, as questões da vida, da própria alimentação deles. Eles sempre têm que estar investigando porque isso aí é fazer ciência, porque a ciência é experimental, né? E é através dessa investigação, dessa busca, dessa curiosidade, é que nós vamos descobrindo coisas. (Professor 16, grifo nosso)

Cabe salientar que a visão positivista é aquela que concebe a ciência como experimental, baseada nos passos relacionados ao método científico: observar, elaborar hipóteses, experimentar, formular leis e teorias que possam fazer previsões sobre os fenômenos, como se pode observar nos grifos correspondentes à fala do Professor 2.

Nas falas dos Professores 4 e 16, nota-se uma valorização da experiência como forma de validar o conhecimento científico, sendo este aspecto também característico da visão positivista. Uma outra particularidade relacionada à concepção positivista é a associação feita entre a ciência e a prática, evidenciando-se o caráter utilitário do conhecimento científico, como na fala do Professor 10.

Estes resultados encontram respaldo no trabalho de Guimarães ${ }^{14}$ em que são discutidas as concepções dos professores de ciências sobre a natureza da ciência e do conhecimento científico. Esta pesquisa mostra que $48,21 \%$ dos professores que responderam às perguntas apresentam concepções relacionadas ao positivismo. No mesmo trabalho é citado Oliveira ${ }^{15}$ no qual a perspectiva positivista é predominante entre professores de química e física do Rio de Janeiro, com um percentual de $50 \%$.

Esta visão encontra-se difundida na sociedade e a mídia tem 
grande parcela de responsabilidade sobre a veiculação desta forma de conceber a ciência. Segundo Cachapuz et al.: ${ }^{12}$

Convém assinalar que esta idéia, que atribui a essência da actividade científica à experimentação, coincide com a de “descobrimento" científico, transmitida, por exemplo pelas bandas desenhadas, pelo cinema e, em geral, pelos meios de comunicação (p. 46).

Discute-se, portanto, se é ruim que os professores sejam positivistas em algumas de suas concepções. Entenda-se, para a condução da discussão, o que seja uma visão positivista. Segundo Schön: ${ }^{16}$

Na primeira metade do século XIX, Augusto Comte expressou pela primeira vez as três principais doutrinas do positivismo. Primeiro, havia a convicção que a ciência empírica não era tão só uma forma de conhecimento, mas a única fonte de conhecimento positivo do mundo. Segundo, havia a intenção de limpar a mente humana do misticismo, da superstição e de outras formas de pseudoconhecimento. E finalmente, havia um programa para estender o conhecimento científico e o controle tecnológico por toda a sociedade humana, para fazer da tecnologia, como disse Comte "não exclusivamente geométrica, mecânica ou química, mas também e principalmente política e moral” (p. 41).

Há então, o reflexo das idéias positivistas na valorização do "cientificamente comprovado": a ciência passa a ser vista como resolução para todos os problemas, até as questões sociais se resolveriam através do conhecimento científico. Mas, no século XX, em decorrência dos avanços e descobertas científicas ocorre uma crise em relação a esse pensamento de que a ciência detém a verdade absoluta, de acordo com Santos: ${ }^{17}$

Em vez da eternidade, a história; em vez do determinismo, a imprevisibilidade; em vez do mecanicismo, a interpenetração, a espontaneidade e a auto-organização; em vez da reversibilidade, a irreversibilidade e a evolução; em vez da ordem, a desordem; em vez da necessidade, a criatividade (p. 28).

A escola como instituição detentora da responsabilidade formal de conduzir a construção do conhecimento científico e formar cidadãos precisa se pautar pelo fato de que a ciência não é detentora de verdades absolutas. Uma nova consciência começa a surgir: a consciência das incertezas e "é preciso aprender a enfrentar estas incertezas, já que vivemos em uma época de mudanças em que os valores são ambivalentes, em que tudo é ligado. E é por isso que a educação do futuro deve se voltar para as incertezas ligadas ao conhecimento". ${ }^{18}$

Assim, não se considera de todo prejudicial ao ensino que os professores ainda utilizem em suas práticas pedagógicas as concepções positivistas das quais é difícil se destituir, desde que, ao utilizar a experiência prática para ensinar química, o professor promova o debate sobre a questão de que não se chega ao conhecimento verdadeiro através do cumprimento das etapas do método científico, esta é uma visão de Bachelard. ${ }^{12}$ É também imprescindível que, ao trabalhar a importância da ciência no desenvolvimento humano, o educador discuta a ambivalência deste processo, pois a tecnologia (resultado direto do avanço do conhecimento científico), além de outras coisas, possibilita ao homem a dominação sobre seus semelhantes e a destruição do meio ambiente.

O uso da programação televisiva pode-se configurar como alternativa na promoção de debates que visem a construção do conhecimento científico no ambiente escolar. É evidente que trabalhar com televisão exige uma leitura do professor no sentido de encontrar e interpretar situações na programação que possam fomentar as discussões e, esta leitura só será possível a partir do conhecimento do professor sobre os fundamentos da epistemologia da ciência, pois, segundo Cachapuz et al.: ${ }^{12}$

A epistemologia ajuda os professores a melhorarem as suas próprias concepções de ciência e à fundamentação da sua acção pedagógico-didáctica. Questionar, discutir e reflectir acerca da pertinência de conexões entre ciêncialepistemologia/educação em ciência é um exercício necessário aos professores para poderem fundamentadamente fazer suas opções científico-educacionais (p. 73).

E quando perguntados se utilizam alguns programas de TV para promover uma discussão sobre assuntos relacionados à ciência, cientista, química, cerca de $94 \%$ dos professores responderam da seguinte forma:

Eu não sou de usar não porque tem a maior dificuldade com o vídeo. Leva os meninos "prá" cá, "prá" lá...mas é falta de arrumar mesmo. (Professor 4)

Em vídeo não. Assim... em vídeo nunca levei, nunca gravei "pra" poder passar nada mas eu sempre levo a discussão. Vocês assistiram? Vocês viram tal programa? (Professor 5)

Programa de TV? Não, nunca. Eu já peguei filmes mas não programas de TV. Porque geralmente os programas de TV não tem muita coisa científica, a não ser Globo Repórter mas... comenta e a gente conversa e já " $t a$ " tudo explicado mesmo. (Professor 8)

Levar em vídeo eu nunca levei. É até engraçado isso, que eu nunca usei o vídeo e a televisão do colégio, sabe, "pra" nada. Mas assim, levar a discussão eu levo como por exemplo quando teve o problema do celobar. (Professor 10)

Eu uso aquele...Telecurso segundo grau. Em que ele coloca bem a questão da ética, mostrando a questão da posição da sociedade. Eu uso também, não da televisão, mas as fitas da $S B Q$, a questão do ar da água, do lixo, da poluição e mostra a questão do nosso cuidado com o outro, com o espaço, com o ambiente. (Professor 16)

É importante ressaltar que as escolas dispõem de recursos audiovisuais como televisão, vídeo e DVD, cabendo ao professor adequar o uso destes recursos ao seu planejamento como uma das maneiras de diversificar o seu trabalho pedagógico. Segundo Pretto: ${ }^{1}$

A presença desses recursos, como fundamento da nova educação, transforma a escola, que passa a ser um novo espaço, físico inclusive, qualitativamente diferente do que vem sendo. Sua função, nessa perspectiva, será a de constituir-se num centro irradiador de conhecimento, com o professor adquirindo, também e necessariamente, uma outra função. Função de comunicador, de articulador das diversas histórias, das diversas fontes de informação. Articulador de um processo que combine a inteligência mental e a inteligência sensivel com a imaginação criadora (p. 115).

O que se torna evidente nas respostas dadas pelos professores é que, apesar de reconhecerem a programação televisiva como fonte de informações incorretas, não a utilizam para tentar reverter o processo 
de formação de conceitos equivocados. A maioria refere-se a programas jornalísticos, informativos ou didáticos como centralizadores de seus debates em sala de aula utilizando a TV como fator motivador sem, no entanto, mostrar o programa na sala de aula, ficando apenas na conversa e discussão.

O problema está no fato de que os programas por eles citados, apesar de serem preparados para informar e ensinar, também apresentam falhas ou equívocos que podem induzir a formação de conceitos errados ou até confrontar conceitos trabalhados na escola. Deve-se sempre estar atento a estas falhas que, quando detectadas, podem ser utilizadas em sala de aula para discussão de conceitos.

Como exemplo, pode-se citar trechos de programas de televisão, como o Fantástico em que o físico Marcelo Gleiser, ao entrevistar o cientista responsável pela teoria de como se originou a vida na Terra, explicou que foram misturadas substâncias inorgânicas em laboratório e simulou-se a atmosfera da Terra primitiva, o que, através de uma reação química, originou as primeiras moléculas de seres vivos em nosso planeta. Observa-se que uma das substâncias é o gás metano, $\mathrm{CH}_{4}$, que é classificada como molécula orgânica e não inorgânica como foi veiculado na reportagem.

A questão que se coloca é que as substâncias são classificadas em orgânicas ou inorgânicas no decorrer do ensino médio visando facilitar a aprendizagem dos alunos. Mas a classificação é apenas um recurso didático, é mais uma das formas de descrever o mundo e representá-lo por meio da simbologia científica. Talvez possa ser construtivo usar esta reportagem ou outras com o mesmo enfoque, a ciência, para trabalhar com os alunos o fato de que, apesar da compartimentalização do ensino escolar, no mundo que existe e nas situações que os cercam, os símbolos e as classificações são apenas "construções desenvolvidas pelo homem para interpretar a natureza". ${ }^{19}$

Programas preparados para divertir, como novelas, filmes e desenhos animados, além de possuírem maior alcance sobre a população acabam gerando visões distorcidas quando têm a ciência como assunto. Tome-se como exemplo as novelas e desenhos animados que apresentam como cientista, personagens homens, sempre fora da realidade, do convívio social e que ao preparar suas invenções e fórmulas sempre explode alguma coisa, ou seja, o estereótipo do cientista veiculado na televisão: alguém que não faz parte da vida comum das pessoas, um louco, um lunático. Isto gera uma visão empobrecida, criando um desinteresse, quando não a rejeição, de muitos estudantes e se converte num obstáculo à aprendizagem. ${ }^{11}$

Esta imagem do cientista veiculada pela mídia reforça na cabeça dos jovens a concepção de que a ciência é algo muito distante da vida deles e que fazer ciência não é para todos, pois um cientista não é uma pessoa normal. Essa é uma dificuldade ou barreira que os professores de química encontram nas primeiras aulas do ensino médio, pois os estudantes chegam com o (pré) conceito sobre o professor e a disciplina, segundo Santos e Mortimer: ${ }^{20}$

As salas de aula são inegavelmente espaços de choque cultural. Dentre os vários fulcros geradores de conflitos destaca-se o choque da cultura primeira dos estudantes com a cultura científica que é imposta nos currículos. Os alunos devem assimilar um conjunto de conhecimentos, atitudes, procedimentos e formas de raciocínio que muitas vezes lhes são completamente estranhos, $e$ isso pode gerar tensão (p. 38).

Tal fato se verifica na fala de cerca de $25 \%$ dos professores, conforme as seguintes falas representativas:

Eles chamam de louco, né? Que esse pessoal não tinha nada "pra" fazer e foi inventar esses "trem" doido. Porque a gente é chamado de doido na escola, né? Eu não sei... eles pensam assim. (Professor 4)

Às vezes, quando eu falo "pra" eles que eu também sou cientista, bacharel,aí eles não acreditam porque eu não passo o perfil que sai na mídia, né?(Professor 12)

Assim, é preciso trabalhar a conscientização dos jovens sobre o papel da mídia nas suas vidas que é o papel maquiador, construtor de uma realidade fantasiosa que almeja encobrir o fato de que todos são manipulados, em maior ou menor grau, para o consumismo e para a ordem vigente de exploração. Segundo Goergen: ${ }^{21}$

Como legitimar uma nova moral em meio à trágica decrepitude da exploração do ser humano, da miserabilização e exclusão de milhares de seres humanos do convívio humano digno, do desrespeito pelos mais primários direitos de cidadania, da corrupção e enganação pública generalizada veiculada pelos meios de comunicação?(p. 55)

Nota-se novamente a importância da Universidade na formação do professor que precisa participar da construção de uma sociedade mais digna através do seu instrumento de trabalho: a educação. De acordo com Pretto:

Para formar esses novos profissionais, as universidades, em especial as públicas, precisarão também ser transformadas. Como principais responsáveis pela formação dos futuros professores, também no interior delas, essas modificações precisam ser sedimentadas. Em função da diversidade de personagens presentes nas universidades, do seu potencial de interdisciplinaridade e do amplo espectro de profissionais que prepara, a universidade é, sem dúvida, o local privilegiado para a pesquisa e discussão das questões ligadas ao novo milênio, em especial quando nos referimos aos meios de comunicação e sua necessária incorporação pela educação (p. 119).

Cabe aqui a pergunta: apesar do que consta nas Orientações Curriculares Nacionais para que os professores trabalhem com os estudantes uma visão crítica dos meios de comunicação, as universidades estão formando os professores neste sentido? É necessário oferecer ao professor ferramentas de trabalho que lhe auxiliem no exercício de uma postura mais criteriosa em relação à mídia junto aos seus alunos.

\section{CONSIDERAÇÕES FINAIS}

O professor de ciências, de química, precisa atuar na busca de condições para que seus alunos desenvolvam uma visão crítica da sociedade, assumindo uma postura de questionamento frente aos meios de comunicação. É um momento de transição, pois há pouco tempo, bastava ensinar os conteúdos de química para ser um bom professor de química, mas "enquanto nos limitarmos a uma educação científica pura e neutra, desvinculada dos aspectos sociais, a nossa contribuição será muito pouca para reverter o atual quadro da sociedade moderna. Essa educação alienante e defeituosa tem até mesmo reforçado o quadro de dominação humana". ${ }^{22}$

Desta forma, usar a programação televisiva para questionar, debater o que está certo, o que não está certo, discutir temas éticos inseridos explícita ou implicitamente na programação, propor ao aluno enxergar com outros olhos, olhos mais atentos, o que lhes é imposto pelos meios de comunicação, pode fazer parte de um ensino de ciências que vise a compreensão, pois, segundo Morin: ${ }^{18}$ "dada 
a importância da educação para a compreensão, em todos os níveis educativos e em todas as idades, o desenvolvimento da compreensão necessita da reforma planetária das mentalidades; esta deve ser a tarefa da educação do futuro".

É válido salientar que toda essa visão crítica necessária ao professor de ciências passa por uma formação epistemológica que lhe possibilite refletir sobre a complexidade do conhecimento científico. Segundo Lôbo e Moradillo:23

As concepções epistemológicas do professor sobre a ciência, sobre o produto da ciência (o conhecimento científico) $e$ sobre o seu papel nos processos de ensino e aprendizagem são de fundamental importância, na medida em que alguns aspectos da sua prática, como a metodologia de ensino, o processo de avaliação e a relação professor-aluno são por elas orientadas (p. 40).

Mais uma vez, o papel da universidade é essencial e relevante na formação de um educador que, no exercício da sua função, possa atuar de maneira consciente e ativa na construção de um projeto de ensino que contemple os fundamentos epistemológicos e políticos da educação.

\section{REFERÊNCIAS}

1. Pretto, N. L.; Uma Escola sem/com Futuro, Papirus: Campinas, 1996.

2. Carmo, D. A. R.; Dissertação de Mestrado, Universidade Federal do Rio de Janeiro, Brasil, 2001.

3. Leal Filho, L. L.; A TV sob Controle: a Resposta da Sociedade ao Poder da Televisão, Summus Editorial: São Paulo, 2006.

4. Fusari, M. F. R.; O Educador e o Desenho Animado que a Criança Vê na Televisão, Loyola: São Paulo, 1985.

5. Rigal, L. Em A Educação no Século XXI: os Desafios do Futuro Imediato; Imberón, F., ed.; Artmed Editora: Porto Alegre, 2000, cap. 3.

6. Loureiro, R.; Fonte, S. S. D.; Indústria Cultural e Educação em Tempos
“Pós-Modernos”, Papirus: São Paulo, 2003.

7. Brasil. Ministério da Educação e Cultura. Secretaria de Educação Fundamental; Parâmetros Curriculares Nacionais: Introdução, MEC: Brasília, 1998.

8. Arroio, A.; Giordan, M.; Química Nova na Escola 2006, n. 24, 8.

9. Salgado, R. G.; Pereira, R. M.; Souza, S. J.; Pela tela da janela: questões teóricas e práticas sobre infância e televisão. Em Cadernos Cedes: televisão, internet e educação: estratégias metodológicas com crianças e adolescentes. Cortez: São Paulo, 2005.

10. Cunha, A. C. B.; Dissertação de Mestrado, Universidade Federal de Goiás, Brasil, 2005.

11. Lüdke, M.; André, M. E. E. D. A.; Pesquisa em Educação: Abordagens Qualitativas, EPU: São Paulo, 1986.

12. Cachapuz, A.; A Necessária Renovação do Ensino das Ciências, Cortez: São Paulo, 2005.

13. Kominski, L.; Giordan, M.; Química Nova na Escola 2002, n. 15, 11.

14. Guimarães, G. M. A.; Dissertação de Mestrado, Universidade Federal de Goiás, Brasil, 2002.

15. Oliveira, R. J.; Revista Brasileira de Estudos Pedagógicos 1991, 72, 335.

16. Shön, D. A.; El Profesional Reflexivo: Cómo Piensan los Profesionales Cuando Actúan, Piados: Barcelona, 1998.

17. Santos, B. S.; Um Discurso Sobre as Ciências, $13^{\mathrm{a}}$ ed., Edições Afrontamento: Porto, 2002.

18 Morin, E.; Os Sete Saberes Necessários à Educação do Futuro, $5^{\mathrm{a}}$ ed., Cortez: São Paulo/UNESCO: Brasília, 2002.

19. Driver, R.; Asoko, H.; Leach, J.; Mortimer, E. F.; Scott, P.; Química Nova na Escola 1999, n. 9, 31.

20. Santos, F. M. T.; Mortimer, E.; Química Nova na Escola 1999, n. 10, 38.

21. Goergen, P.; Pós-modernidade, Ética e Educação, Autores Associados: São Paulo, 2001.

22. Santos, W. L. P.; Schnetzler, R. P.; Educação Química: Compromisso com a Cidadania, $3^{\mathrm{a}}$ ed., Unijuí: Ijuí, 2003.

23. Lôbo, S. F.; Moradillo, E. F.; Química Nova na Escola 2003, n. 17, 39. 